\title{
Regulatory role of miRNA-26a in neonatal sepsis
}

\author{
QI CHENG ${ }^{1,2}$, LILI TANG ${ }^{3}$ and YIBIAO WANG ${ }^{4}$ \\ ${ }^{1}$ Department of Pediatrics, The Second Hospital of Shandong University, Jinan, Shandong 250033; \\ ${ }^{2}$ Department of Pediatrics, Liaocheng People's Hospital, Liaocheng, Shandong 252000; \\ ${ }^{3}$ Department of Pediatrics, Gaotang County People's Hospital, Liaocheng, Shandong 252800; \\ ${ }^{4}$ Department of Pediatrics, The Second Hospital of Shandong University, Jinan, Shandong 250000, P.R. China
}

Received January 11, 2018; Accepted June 20, 2018

DOI: $10.3892 /$ etm.2018.6779

\begin{abstract}
The present study aimed to investigate the expression of microRNA (miRNA) 26a in blood mononuclear cells and serum in neonatal sepsis, as well as its role in the disease pathogenesis. In total 28 cases of neonatal sepsis were included in the study. The mRNA expression levels of miRNA-26a and interleukin (IL)-6 in the blood mononuclear cells and serum samples were detected by reverse transcription-quantitative polymerase chain reaction. The protein expression of IL-6 was detected by western blot analysis and ELISA. The in vitro septic environment was simulated by lipopolysaccharide (LPS) in THP-1 cells, and the expression of miRNA-26a and IL-6 were determined. Interaction between miRNA-26a and IL-6 was confirmed by a dual-luciferase reporter assay. Compared with the control group, the mRNA and protein expression levels of IL-6 in the blood mononuclear cells and serum samples from the neonates with sepsis were significantly elevated, while the expression of miRNA-26a was significantly decreased. In addition, similar results were observed in the LPS-induced septic models in THP-1 cells. Furthermore, the results of the dual-luciferase reporter assay demonstrated that IL-6 was the direct target of miRNA-26a. The expression of IL-6 was significantly upregulated in the blood mononuclear cells and serum in neonatal sepsis, which may be associated with the downregulation of miRNA-26a. miRNA-26a may regulate the disease pathogenesis and immune responses.
\end{abstract}

\section{Introduction}

Neonatal sepsis refers to a severe systematic infectious disease in neonates induced by a variety of pathogens (such as bacteria, fungi, and viruses). These pathogens invade into the blood circulation, which grow, proliferate, and metabolize

Correspondence to: Dr Yibiao Wang, Department of Pediatrics, The Second Hospital of Shandong University, 247 Beiyuan Street, Jinan, Shandong 250000, P.R. China

E-mail:wangyibiao1123@126.com

Key words: neonatal sepsis, interleukin-6, microRNA-26a, THP-1 cells in the blood, body cells, organs, and tissues, synthesizing various toxins to cause infection. It has been reported that, the incidence of neonatal sepsis is $1-5 \%$ in developed countries, while it is as high as 49-179\%o (1). In 2010, 7.6 million children under the age of 5 years have died from infection throughout the world, in which neonates have accounted for $40 \%$ (2). Due to the fact that neonatal sepsis is caused by infection, in the inflammatory and anti-inflammatory responses, all the tissues and organs in the body might be involved, and the system functions might have disorders. It has been widely accepted that the activation of neutrophils, lymphocytes, and mononuclear macrophages, as well as the release of endogenous mediators, play important roles in the pathogenesis and development of neonatal sepsis (3-5).

Interleukin-6 (IL-6) is an important factor in the immune response. Lymphokines produced by the activated monocytes and macrophages could transform the B-cell precursors into the antibody-generating cells. IL- 6 could also cooperate with colony stimulating factors to promote the growth and differentiation of primary bone marrow-derived cells, enhancing the lysis function of natural killer cells (6-8). There have been numerous studies concerning the regulatory role of IL-6 in the pathogenesis of neonatal sepsis $(4,9,10)$. Moreover, there has been research development in the regulating mechanism of IL-6, concerning various mRNAs and microRNA (miRNAs). It has been shown that miRNA-365 could negatively regulate the expression of IL- 6 in the HEK293 and HELA cells (11). However, the regulating effect of miRNA-26a on IL-6 in the blood mononuclear cells in neonates with sepsis has not yet been reported.

In this study, the role of miRNA-26a in the pathogenesis of neonatal sepsis and its relationship with IL-6 were investigated. The mRNA and protein expression levels of IL-6 in the blood monocytes and serum in neonatal sepsis were detected by the quantitative real-time PCR, western blot analysis, and enzyme-linked immunosorbent assay (ELISA). The interaction between IL-6 and miRNA-26a was predicted and confirmed by the bioinformatics analysis and dual-reporter assay.

\section{Materials and methods}

Study subjects. Totally 28 cases of neonates with sepsis, 16 males and 12 females, weighing $2.2 \pm 2.8 \mathrm{~kg}$, were included in this study, who were admitted to our hospital, from 
December 2012 to March 2017. The blood samples were collected. Moreover, 32 cases of normal neonates were used as control, 19 males and 13 females, weighing $2.1 \pm 3.0 \mathrm{~kg}$. These neonatal sepsis cases and control subjects were pathologically confirmed by the blood test (12). Prior written and informed consent for each subject were obtained and the study was approved by the Ethics Committee of the Second Hospital of Shandong University (Jinan, China).

Sample preparation. For the collection of peripheral blood serum, the gradient centrifugation combined with adherent separation method was used. Totally $1-5 \mathrm{ml}$ peripheral venous blood was harvested and stored at $4^{\circ} \mathrm{C}$ for $1-2 \mathrm{~h}$. Then the upper serum was collected and centrifuged at $400 \mathrm{x} \mathrm{g}$ for $10 \mathrm{~min}$, which was stored at $-70^{\circ} \mathrm{C}$.

For the collection of peripheral blood mononuclear cells, based on the previous work, the blood cytosolic fraction was equally diluted with Hanks solution. Totally $5 \mathrm{ml}$ lymphocyte separation solution was added into the 15-ml BD tube. The heparin-anticoagulated venous blood was equally mixed with IMDM without bovine serum (1:1), which was slowly superimposed on the stratifying solution layer with a dropper, followed by gentle addition of $8 \mathrm{ml}$ equally diluted cytosolic fraction. After centrifugation at $400 \mathrm{x}$ g for $30 \mathrm{~min}$, the mononuclear cells in the narrow white cloud layer at the interface between the upper and middle cloud layers were collected with the capillary pipette. These cells were washed twice with the D-HANK'S solution, followed by centrifugation at $300 \mathrm{x} g$ for $10 \mathrm{~min}$. The cells were then seeded onto the $9-\mathrm{cm}^{2}$ cell culture dish, at the density of $3 \times 10^{6}$ cells/dish, and cultured in a $37^{\circ} \mathrm{C}, 5 \% \mathrm{CO}_{2}$ incubator for 1-2 h. The adherent cells were the mononuclear cells.

Reverse transcription-quantitative polymerase chain reaction. The mRNA expression levels of IL-6 were detected with the quantitative real-time PCR. Total RNA was extracted with the TRIzol. Totally $1 \mu \mathrm{g}$ total RNA was used for the reverse transcription PCR to obtain the cDNA template. Quantitative real-time PCR was performed with the miRcute miRNA quantitative real-time PCR detection kit (FP401; Tiangen, Beijing, China) on the PCR-iQ5 machine (Bio-Rad, Hercules, CA, USA). The primer sequences were as follows: IL-6 forward, 5'-GGC ACTGGCAGAAAACAACC-3' and reverse, 5'-GCAAGT CTCCTCATTGAATCC-3'; GAPDH forward, 5'-GGGAAA CTGCGGCGTGAT-3' and reverse, 5'-AAAGGTGGAGGA GTGGGT-3'. The $25-\mu 1$ reaction system included $1 \mu \mathrm{l}$ cDNA, $12.5 \mu \mathrm{l} \mathrm{SYBR}$ Premix EXTaqTM, $10 \mu \mathrm{M}$ primer each, and

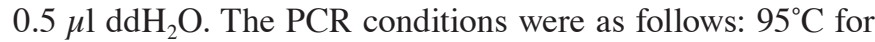
$30 \mathrm{sec} ; 95^{\circ} \mathrm{C}$ for $5 \mathrm{sec}, 57^{\circ} \mathrm{C}$ for $30 \mathrm{sec}$, for totally 45 cycles. The additional lysis curve analysis conditions were as follows: $95^{\circ} \mathrm{C}$ for $15 \mathrm{sec}, 60^{\circ} \mathrm{C}$ for $23 \mathrm{sec}$, and $95^{\circ} \mathrm{C}$ for $15 \mathrm{sec}$. The target expression levels were determined with the $2^{-\Delta \Delta \mathrm{Ct}}$ method. GAPDH was used as internal reference.

For the detection of miRNA-26a, the following primer sequences were used: miRNA-26a forward, 5'-CTGTCAACG ATACGCTAC-3' and reverse, 5'-GTAATCCAGGATAGG CTG-3'; and U6 forward, 5'-CTTCGGCAGCACATATAC-3' and reverse, 5'-GAACGCTTCACGAATTTGC-3'. The PCR conditions were as follows: $90^{\circ} \mathrm{C}$ for $60 \mathrm{sec} ; 95^{\circ} \mathrm{C}$ for $15 \mathrm{sec}$, $60^{\circ} \mathrm{C}$ for $30 \mathrm{sec}$, for totally 40 cycles. U6 was used as internal reference.
Western blot analysis. The protein expression levels of IL-6 in the blood mononuclear cells were detected by the western blot analysis. Cells were lysed with the lysis. Protein concentration was determined with the BCA method (RTP7102; RealTimes, Beijing, China). Totally $20 \mu \mathrm{g}$ protein sample was separated by the $10 \%$ SDS-PAGE, and then electronically transferred onto the membrane. The membrane was blocked by $5 \%$ non-fat milk at room temperature for $1 \mathrm{~h}$, and then incubated with rabbit anti-human anti-IL-6 primary antibody (ab6672; 1:1,000 dilution), or rabbit anti-human anti- $\beta$-actin primary antibody (ab129348; 1:5,000 dilution; both Abcam, Cambridge, MA, USA), at $4^{\circ} \mathrm{C}$ overnight. The membrane was then incubated with goat anti-rabbit secondary antibody (ab6721; 1:3,000 dilution; Abcam) at room temperature for $1 \mathrm{~h}$. Color was developed with the ECL method (ab65623; Abcam), and the protein band images were analyzed with the ImageLab software (version 3.0). $\beta$-actin was used as internal reference.

ELISA. The serum IL-6 contents were detected with the ELISA kits (ab178013; Abcam). Briefly, totally $10 \mu \mathrm{l}$ serum sample was added into the detection well, while $50 \mu \mathrm{l}$ standard samples were added into the standard wells, followed by $40 \mu \mathrm{l}$ sample diluting solution. Except for the blank wells, $100 \mu$ l HRP-conjugated detection antibody was added into the standard and sample wells. The plate was sealed and incubated for $1 \mathrm{~h}$. After washing, substrates A and B (50 $\mu \mathrm{l} \mathrm{each)} \mathrm{were} \mathrm{added} \mathrm{into} \mathrm{the} \mathrm{wells,}$ followed by incubation at $37^{\circ} \mathrm{C}$ for $15 \mathrm{~min}$. Totally $50 \mu \mathrm{l}$ stop solution was added into each well, and the OD value at $450 \mathrm{~nm}$ was determined within $15 \mathrm{~min}$.

Bioinformatics analysis. The upper regulating miRNAs of IL-6 were predicted with the bioinformatics analysis. Based on the literature mining, the regulating genes for IL- 6 were predicted with the following prediction software: miRanda (http://www.microma.org/rnicroma/home. do), TargetSean (www.targetscan.org), PiTa (http://genie. weizmann.ac.il/pubs/mir07/mir07_data.html), RNAhybrid (http://bibiserv.techfak.uni-bielefeld.de/rnahybrid/), and PICTA (http://pictar.mdc-berlin.de/).

In vitro sepsis model establishment. In intro sepsis model was established with the lipopolysaccharide (LPS) induction in Human monocytic leukemia THP-1 cells (TCHu 57; Chinese Academy of Sciences Cell Bank, Shanghai, China) THP-1 cells were transfected with $1 \mu \mathrm{g} / \mathrm{ml}$ LPS for $24 \mathrm{~h}$ to simulate the sepsis environment. The expression levels of miRNA-26a and IL-6 were detected.

Dual-luciferase reported assay. The wild-type and mutant IL-6 3'-UTR fragments for miRNA-26a were synthesized, with the Spe-1 and HindIII restriction sites on each end (Sangon Biotech, Shanghai, China). These two fragments were cloned into the pMIR-REPORT luciferase reporter plasmid (E1980; Promega Corporation, Madison, WI, USA). These plasmids containing wild-type and mutant 3'-UTR (each $0.8 \mu \mathrm{g}$ ) were transfected into the 293T cells with the liposome, followed by the transfection of agomiRNA-26a (100 nM; Sangon Biotech) for $24 \mathrm{~h}$. The cells were lysed, and the luciferase was detected with the GloMax 20/20 luminometer (Promega Corporation). Renilla was used as internal reference. 

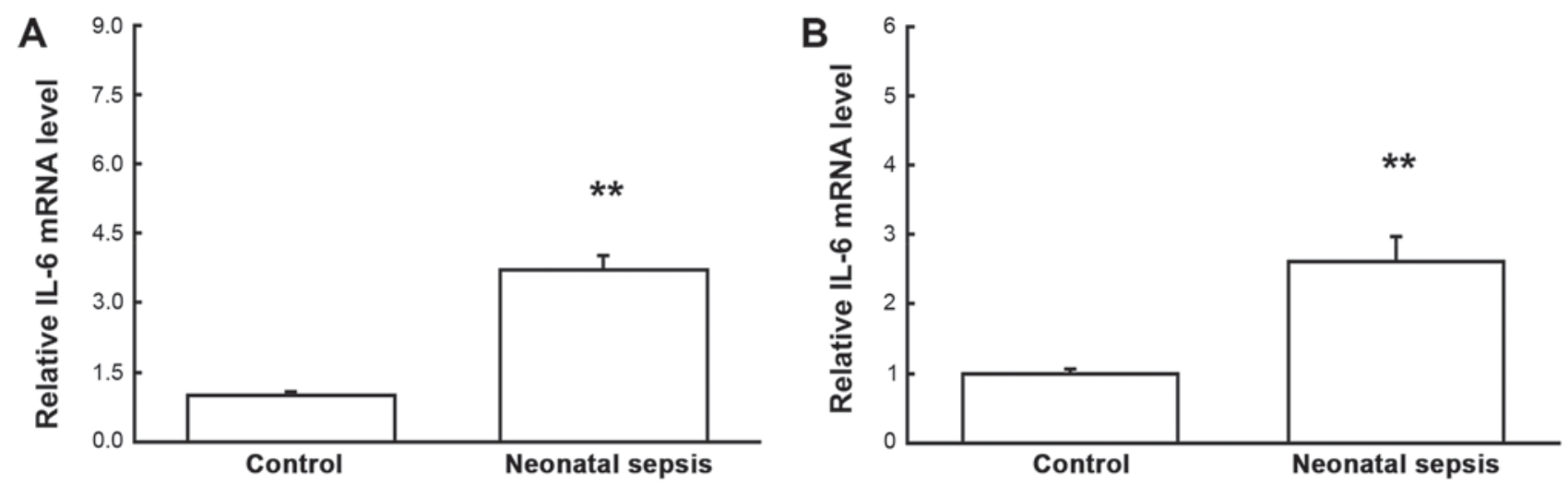

Figure 1. mRNA expression levels of IL-6 in blood mononuclear cells and serum samples in neonatal sepsis. Reverse transcription-quantitative polymerase chain reaction was performed to detect the mRNA expression levels of IL-6 in the (A) blood mononuclear cells and (B) serum samples in the cases of neonatal sepsis. ${ }^{* *} \mathrm{P}<0.01$ vs. the control group. IL, interleukin.

Statistical analysis. Data were expressed as mean \pm standard deviation. SPSS 18.0 software was used for statistical analysis. After the normality test, one-way ANOVA was performed for the multiple comparisons, with the LSD and SNK methods for the homogeneous variance, or the Tamhane's T2 or Dunnett's T3 method for the heterogeneous variance. $\mathrm{P}<0.05$ was considered to indicate a statistically significant difference.

\section{Results}

Changed expression levels of IL-6 in neonatal sepsis. To investigate the mRNA and protein expression levels of IL-6 in the blood mononuclear cells and serum, quantitative real-time PCR, western blot analysis, and ELISA were performed, respectively. Our results from the quantitative real-time PCR showed that, compared with the control group, the mRNA expression levels of IL-6 in both the blood mononuclear cells and serum samples were significantly elevated for neonatal sepsis (both $\mathrm{P}<0.05$ ) (Fig. 1). Similar results were obtained for the detection of protein expression levels of IL-6. Western blot analysis showed that, compared with the control group, the protein expression levels of IL-6 in the blood mononuclear cells for the neonatal sepsis were significantly increased $(\mathrm{P}<0.05)$. Moreover, ELISA showed that, compared with the control group, the serum IL-6 contents were significantly increased for the neonatal sepsis $(\mathrm{P}<0.05)$ (Fig. 2). Taken together, these results suggest that both the mRNA and protein expression levels of IL-6 in the blood mononuclear cells are elevated in neonatal sepsis, leading to elevated serum IL-6 contents, which might be involved in regulating the pathogenesis of neonatal sepsis.

Changed expression levels of miRNA-26a in neonatal sepsis. Based on the bioinformatics prediction analysis, miRNA-26a was recognized as the up-stream regulator for IL-6 (Fig. 3). Therefore, the expression levels of miRNA-26a in neonatal septic samples were analyzed by the quantitative real-time PCR. Our results showed that compared with the control group, the expression levels of miRNA-26a were significantly declined in the neonatal septic samples $(\mathrm{P}<0.05)$ (Fig. 4), indicating that miRNA-26 might contribute to the pathogenic process of neonatal sepsis, probably via regulating the expression of target gene IL-6 on the transcription level.
Changed expression levels of miRNA-26a and IL-6 in in vitro septic model. The in vitro septic model was established by LPS induction in the THP-1 cells, and the expression levels of miRNA-26a and IL-6 were analyzed. Our results showed that, compared with the control group, the miRNA-26a level was significantly declined, while the IL-6 expression level was significantly elevated, in the LPS-induced THP-1 cells (Fig. 5). These results confirm the expression patterns of and the regulatory relationship between miRNA-26a and IL-6 in the neonates with sepsis.

Direct interaction between miRNA-26a and IL-6. To confirm the direct interaction between miRNA-26a and IL-6, dual-luciferase reporter assay was performed. Our results showed that, compared with the NC group, the co-transfection of agomiRNA-26a and pMIR-REPORT plasmids significantly declined the luciferase in the cells $(\mathrm{P}<0.05)$, while no significant changes were observed in the cells transfected with the plasmid containing mutant 3'-UTR ( $\mathrm{P}>0.05)$ (Fig. 6). These results suggest that miRNA-26a could directly bind with the 3'-UTR of IL-6 to regulate the gene expression.

\section{Discussion}

In the present study, the expression levels of miRNA-26a in the blood mononuclear cells and serum samples from the neonatal sepsis cases were analyzed, as well as its down-stream target gene IL-6 (mRNA and protein expression levels). Moreover, in vitro models were established by the LPS induction in THP-1 cells, and the expression levels of miRNA-26a and IL-6 were detected. The mechanism through which miRNA-26a targeted on its down-stream IL-6 to contribute to the pathogenesis of neonatal sepsis was primarily investigated.

Neonatal infectious disease is still one of the commonly seen diseases in the neonatal period, and severe cases could induce sepsis, multiple organ failure, and even death. With the development of economy and medical technologies, although the survival rate of neonates has been rising over the past decades, more than 1 million newborns still die of serious infection each year, according to the World Health Organization (WHO), in which the death cases associated with neonatal sepsis or pneumonia might be up to 1 million (13). 
A
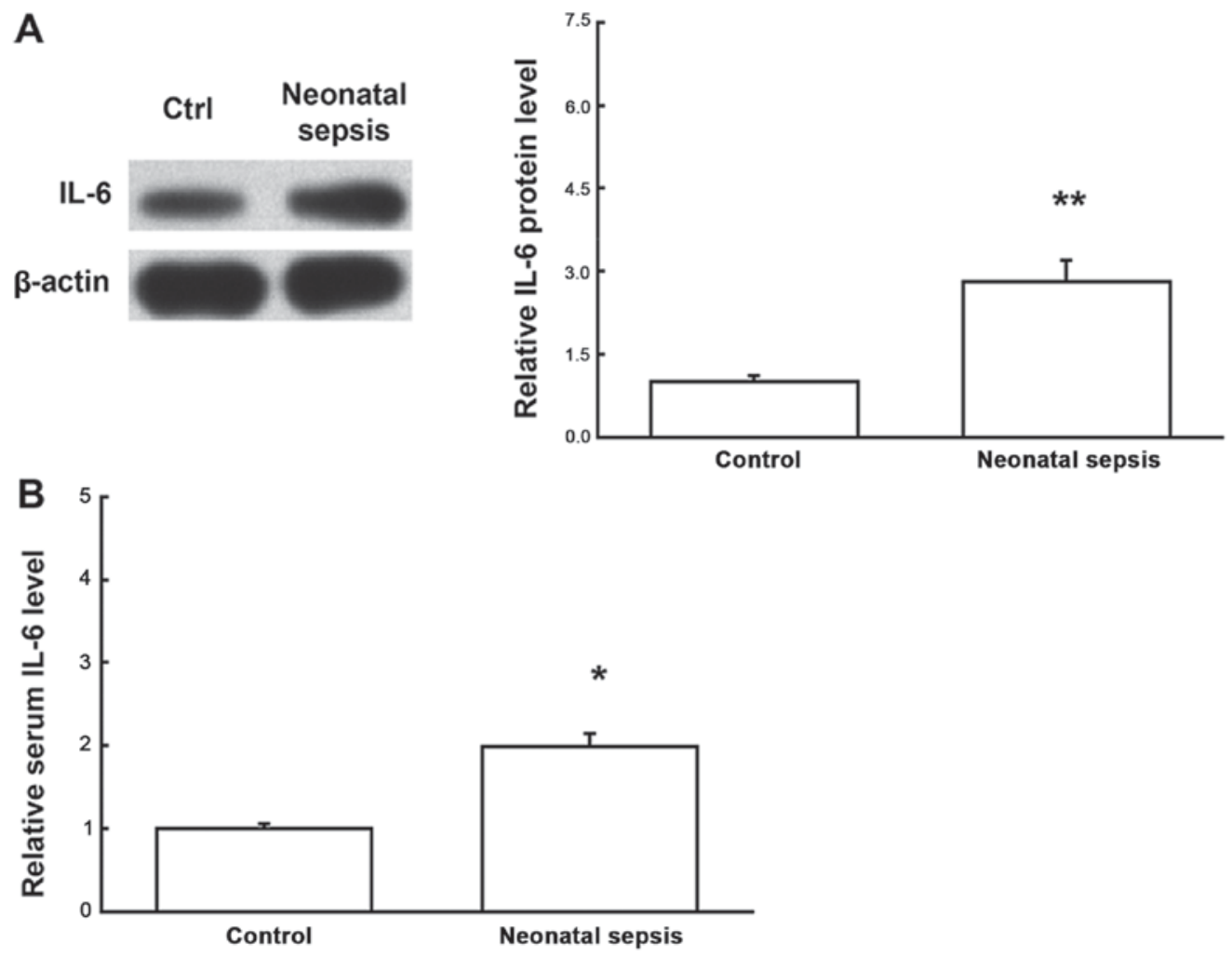

Figure 2. Protein expression levels of IL-6 in blood mononuclear cells and serum samples in neonatal sepsis. Western blot analysis and ELISA were performed to detect the protein expression of IL- 6 in the (A) blood mononuclear cells and (B) serum samples, respectively in the neonatal sepsis. ${ }^{*} \mathrm{P}<0.05$ and ${ }^{* *} \mathrm{P}<0.01$ vs. the control group. IL, interleukin; ELISA, enzyme-linked immunosorbent assay.

\section{3' ucggauaggaccuaaUGAACUu 5' hsa-miRNA-26a || || | 195:5' uuuuuaagaaguaccACUUGAa 3' IL-6}

Figure 3. Bioinformatics analysis. The miRNA-26a was predicted as the up-stream regulator of IL-6 according to the bioinformatics analysis. IL, interleukin; miRNA, microRNA.

It is widely accepted that the activation of neutrophils, lymphocytes, and mononuclear macrophages, and the release of endogenous mediators, might play key roles in the pathogenesis and development of neonatal sepsis. Recently, evidence suggests that the role of cytokines cannot be ignored either. It has been shown that the elevated levels of CXCR4, CXCL12, TNF- $\alpha$, IL-6, and IL-8 are associated with the neonatal sepsis infection $(10,14-16)$.

IL-6 is a potent cytokine synthesized by mononuclear cells, phagocytes, $\mathrm{T}$ cells, B cells, vascular endothelial cells, fibroblasts, and other cells in response to IL-1 and small amount of TNF- $\alpha$ (17). Under normal conditions, the IL-6 content is minimal, with, however, high biological activity, exerting functions mainly through the paracrine and autocrine effects (18). In the inflammation, IL-6 can induce the production of $\mathrm{C}$-reactive protein and fibrinogen in the body, which can also promote the formation of thrombosis (19). Elevated IL-6 level in the body can induce the pathogenesis of inflammatory diseases by binding to the IL- 6 receptor, such as rheumatoid arthritis and Crohn's disease (20). In the rheumatoid arthritis, IL-6 can stimulate the T lymphocytes and B lymphocytes to secret inflammatory mediators, promoting the maturation of B lymphocytes and enhancing the effects of IL-1 $\beta$ and TNF- $\alpha$. In the inflammatory responses, IL- 6 exerts chemotaxis-inducing effects on other inflammatory cells, such as lymphocytes and mononuclear macrophages (21).

To further explore the specific role of IL-6 in the pathogenesis of trauma and infection, Riedemann et al (22) have shown that IL- 6 could significantly promote the expression of C5a on the mRNA level, suggesting that IL-6 enhances the secondary inflammatory mediator $\mathrm{C} 5 \mathrm{a}$ to exert its pro-inflammatory effects. Moreover, Pritts et al (23) have shown that nuclear NF-kb and activated protein 1 (AP-1) are involved in the stimulating signal transition process in the synthesis of IL-6 within effector cells. Although great progress has been made concerning the investigation of the role of IL-6 in the neonatal sepsis pathogenesis, the detailed cellular and molecular mechanisms remain to be further explored. In this study, elevated expression levels of IL-6 (mRNA and protein levels) were detected in both the blood mononuclear cells and serum samples from the neonates with sepsis. These results suggest that inflammatory infection might activate the mononuclear cells and lymphocytes, which could secret large amounts of IL-6 to induce large-scale antigen immune response. These findings were in line with the responses of the somatic cell damage.

miRNAs are important gene regulatory factors widely involved in a variety of pathophysiological processes, such as tumor cell proliferation, invasion and metastasis, hypertension, diabetes, and atherosclerosis $(24,25)$. The dysregulation of miRNA-26a contributes to various biological processes, including the natural immune responses against the invasion of pathogenic microorganisms, the development and 

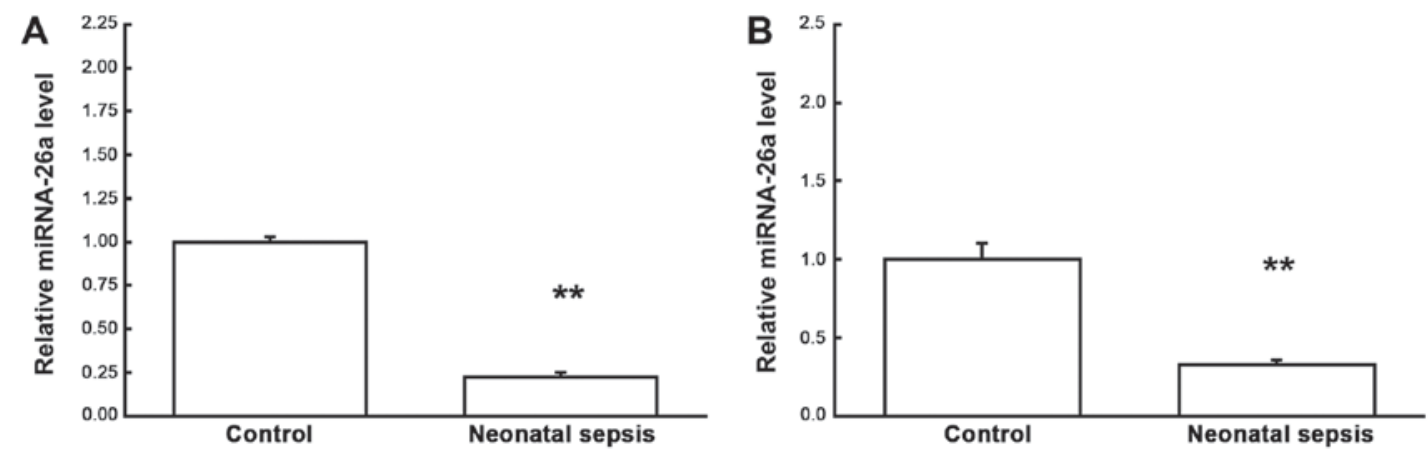

Figure 4. Expression levels of miRNA-26a in blood mononuclear cells and serum samples in neonatal sepsis. Reverse transcription-quantitative polymerase chain reaction was performed to detect the expression levels of miRNA-26a in the (A) blood mononuclear cells and (B) serum samples in the cases of neonatal sepsis. ${ }^{* *} \mathrm{P}<0.01$ vs. the control group. miRNA, microRNA.

A
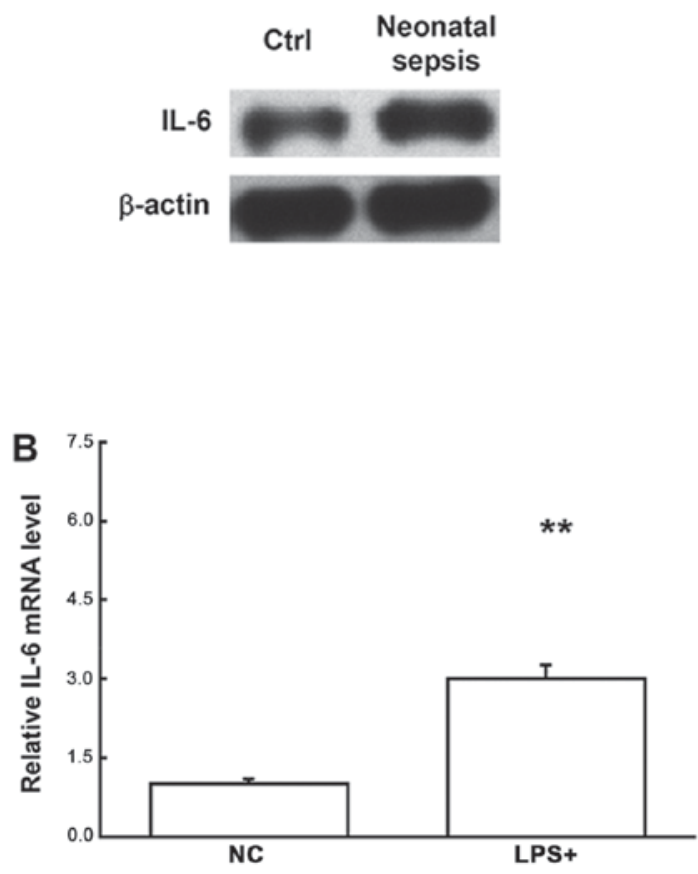
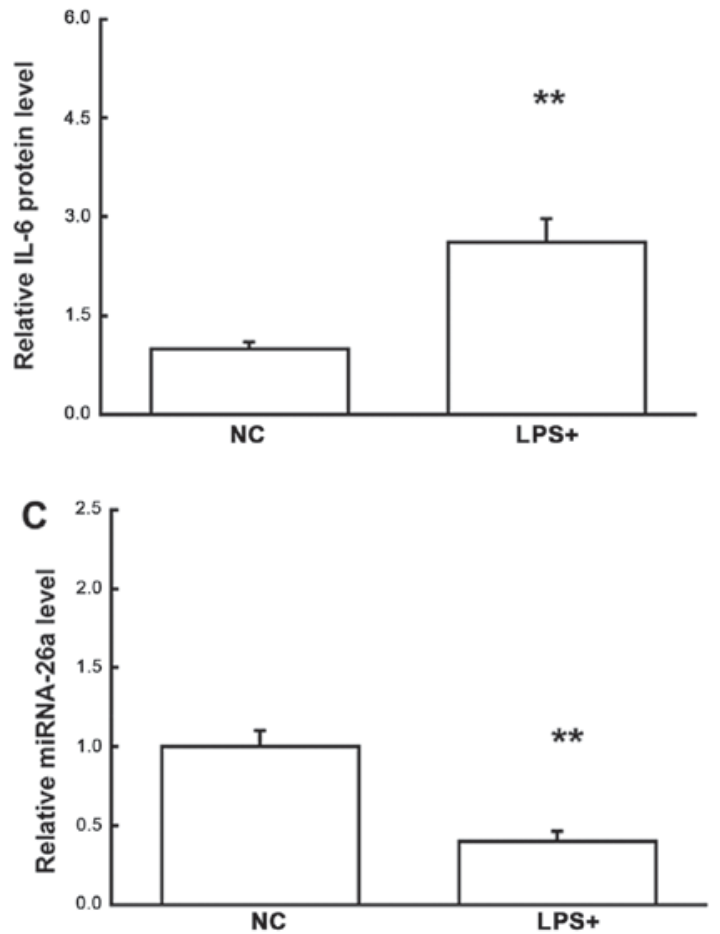

Figure 5. Expression levels of IL-6 and miRNA-26a in LPS-induced THP-1 cells. THP-1 cells were induced with LPS to simulate the in vitro septic environment. (A) The protein and (B) mRNA expression levels of IL-6 in the LPS-induced THP-1 cells were detected by RT-qPCR and western blot analysis, respectively. (C) The expression levels of miRNA-26a in the LPS-induced THP-1 cells were detected by RT-qPCR. "* P<0.01 vs. the control group. RT-qPCR, reverse transcription-quantitative polymerase chain reaction; IL, interleukin; LPS, lipopolysaccharide; miRNA, microRNA.

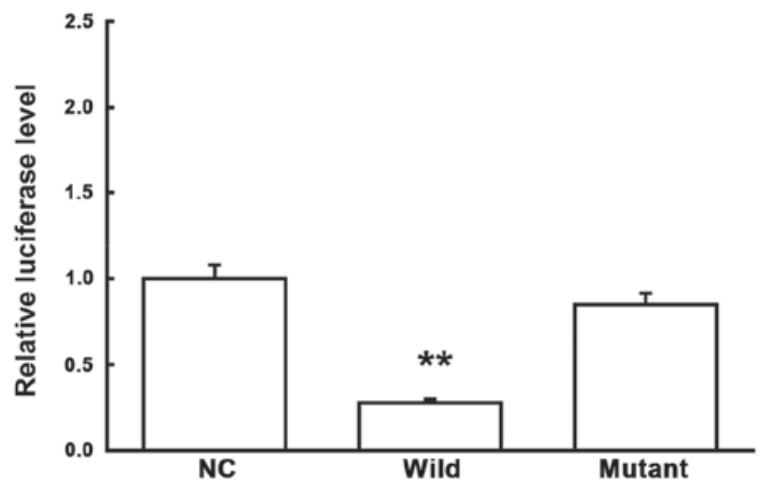

Figure 6. Dual-luciferase reporter assay. Direct interaction between miRNA-26a and IL-6 was confirmed by a dual-luciferase reporter assay. ${ }^{* *} \mathrm{P}<0.01$ vs. the NC group. NC, negative control; miRNA, microRNA; IL, interleukin. differentiation of organs and/or tissues, and the pathogenesis of various solid tumors and hematopoietic malignancy. miRNA-26a has been shown to be able to activate the innate immune responses by controlling the secretion of various inflammatory chemokines $(26,27)$. Meanwhile, miRNA-26a also plays an important role in the regulation of stem cell differentiation. For example, miRNA-26a has been shown to be involved in the differentiation of hepatic stem cells into mature hepatocytes and biliary tract cells, as well as the differentiation of adipose-derived stem cells into osteoblasts, by regulating the transcription factor Smad family $(28,29)$. miRNA-26a is expressed in a variety of cancer cells and cancerous tissues, which can inhibit the proliferation of nasopharyngeal carcinoma, breast cancer, and HCC cells (30-34). Based on the bioinformatics prediction, our results showed that 
miRNA-26a was closely related to IL-6, which was likely to be an up-stream miRNA regulating IL-6 expression. Previous literature has shown that miRNA-26a negatively regulates the expression levels of IL-6 (35). In this study, our results showed that the miRNA-26a expression level was significantly declined, while the expression level of IL-6 was significantly elevated, in the mononuclear cells from the neonatal sepsis cases. Moreover, similar results were observed in the expression levels of miRNA-26a and IL-6 in the serum samples from the neonatal sepsis. These results suggest that the downregulated miRNA-26a in the mononuclear cells could increase the expression level of IL-6, as well as its secretion into the serum in neonatal sepsis. Moreover, the serum expression levels of miRNA-26a and IL-6 might, to some extent, reflect the inflammatory responses and tissue injuries. In addition, THP-1 cells were induced by LPS to simulate the in vitro septic environment, and the results further confirmed the expression patterns of miRNA-26a and IL-6, and their interaction. Furthermore, the dual-luciferase reporter assay showed that IL-6 was the direct target of miRNA-26a.

In conclusion, our results showed that, in the neonatal sepsis, the serum miRNA-26a content was significantly declined, which regulated the expression levels of the target gene IL-6, to further changing the expression levels of related proteins. These findings might contribute to the understanding of the roles of miRNA-26a and IL-6 in the pathogenesis of neonatal sepsis.

\section{Acknowledgements}

Not applicable.

\section{Funding}

No funding was received.

\section{Availability of data and materials}

The datasets used and/or analyzed during the current study are available from the corresponding author on reasonable request.

\section{Authors' contributions}

QC conceived and designed the study, read and analyzed the documents and collected and analyzed data. LT read and analyzed the documents and collected and analyzed the data. YW conceived and designed the study, read and analyzed the documents, drafted and revised the manuscript and gave the final approval of the version to be published. All authors take responsibility for the content of the paper.

\section{Ethics approval and consent to participate}

The present study was approved by the Ethics Committee of the Second Hospital of Shandong University and written informed consent was obtained from all participants.

\section{Patient consent for publication}

Not applicable.

\section{Competing interests}

The authors declare that they have no competing interests.

\section{References}

1. Satar M and Ozlü F: Neonatal sepsis: A continuing disease burden. Turk J Pediatr 54: 449-457, 2012.

2. Liu L, Johnson HL, Cousens S, Perin J, Scott S, Lawn JE, Rudan I, Campbell H, Cibulskis R, Li M, et al: Global, regional and national causes of child mortality: An updated systematic analysis for 2010 with time trends since. Lancet 379: 2151-2161, 2012.

3. Raymond SL, Stortz JA, Mira JC, Larson SD, Wynn JL and Moldawer LL: Immunological defects in neonatal sepsis and potential therapeutic approaches. Front Pediatr 5: 14, 2017.

4. Wu YQ, Shen J, Zhou QL, Zhao HW, Liu LR and Liu X: Interleukin-6 and interleukin-8 in diagnosing neonatal septicemia. J Biol Regul Homeost Agents 30: 1107-1113, 2016.

5. Delanghe JR and Speeckaert MM: Translational research and biomarkers in neonatal sepsis. Clin Chim Acta 451: 46-64, 2015.

6. Anderson AE, Pratt AG, Sedhom MA, Doran JP, Routledge C, Hargreaves B, Brown PM, Lê Cao KA, Isaacs JD and Thomas R: IL-6-driven STAT signalling in circulating CD4+ lymphocytes is a marker for early anticitrullinated peptide antibody-negative rheumatoid arthritis. Ann Rheum Dis 75: 466-473, 2016.

7. Tezono K, Sarker KP, Kikuchi H, Nasu M, Kitajima I and Maruyama I: Bioactivity of the vascular endothelial growth factor trapped in fibrin clots: Production of IL-6 and IL-8 in monocytes by fibrin clots. Haemostasis 31: 71-79, 2001.

8. Vila N, Reverter JC, Yague J and Chamorro A: Interaction between interleukin- 6 and the natural anticoagulant system in acute stroke. J Interferon Cytokine Res 20: 325-329, 2000.

9. Celik HT, Portakal O, Yigit S, Hascelik G, Korkmaz A and Yurdakok M: Efficacy of new leukocyte parameters versus serum C-reactive protein, procalcitonin and interleukin-6 in the diagnosis of neonatal sepsis. Pediatr Int 58: 119-125, 2016.

10. Steinberger E, Hofer N and Resch B: Cord blood procalcitonin and Interleukin- 6 are highly sensitive and specific in the prediction of early-onset sepsis in preterm infants. Scand J Clin Lab Invest 74: 432-436, 2014.

11. Xu Z, Xiao SB, Xu P, Xie Q, Cao L, Wang D, Luo R, Zhong Y, Chen HC and Fang LR: miR-365, a novel negative regulator of interleukin- 6 gene expression, is cooperatively regulated by $\mathrm{Sp} 1$ and NF-kappaB. J Biol Chem 286: 21401-21412, 2011.

12. Subspecialty Group of Neonatology Pediatric Society Chinese Medical Association; Editorial Board Chinese Journal of Pediatrics. Protocol for diagnosis and treatment of neonatal septicemia. Zhonghua Er Ke Za Zhi 41: 897-899, 2003 (In Chinese).

13. Qazi SA and Stoll BJ: Neonatal sepsis: A major global public health challenge. Pediatr Infect Dis J 28 (1 Suppl): S1-S2, 2009.

14. Zhou M, Cheng S, Yu J and Lu Q: Interleukin-8 for diagnosis of neonatal sepsis: A meta-analysis. PLoS One 10: e0127170, 2015.

15. Tunc T, Cekmez F, Cetinkaya M, Kalayci T, Fidanci K, Saldir M, Babacan O, Sari E, Erdem G, Cayci T, et al: Diagnostic value of elevated CXCR4 and CXCL12 in neonatal sepsis. J Matern Fetal Neonatal Med 28: 356-361, 2015.

16. Lv B, Huang J, Yuan H, Yan W, Hu G and Wang J: Tumor necrosis factor- $\alpha$ as a diagnostic marker for neonatal sepsis: A meta-analysis. ScientificWorldJournal 2014: 471463, 2014.

17. DeLong WG Jr and Born CT: Cytokines in patients with polytrauma. Clin Orthop Relat Res: 57-65, 2004.

18. Stover JF, Sakowitz OW, Schoning B, Rupprecht S, Kroppenstedt SN, Thomale UW, Woiciechowsky C and Unterberg AW: Norepinephrine infusion increases interleukin-6 in plasma and cerebrospinal fluid of brain-injured rats. Med Sci Monit 9: Br382-Br388, 2003.

19. Baeuerle PA and Henkel T: Function and activation of NF-kappa $B$ in the immune system. Annu Rev Immunol 12: 141-179, 1994.

20. Tone M, Powell MJ, Tone Y, Thompson SA and Waldmann H: IL-10 gene expression is controlled by the transcription factors Sp1 and Sp3. J Immunol 165: 286-291, 2000.

21. Luo Q, Ma X, Wahl SM, Bieker JJ, Crossley M and Montaner LJ: Activation and repression of interleukin-12 p40 transcription by erythroid Kruppel-like factor in macrophages. J Biol Chem 279: 18451-18456, 2004. 
22. Riedemann NC, Neff TA, Guo RF, Bernacki KD, Laudes IJ, Sarma JV, Lambris JD and Ward PA: Protective effects of IL-6 blockade in sepsis are linked to reduced C5a receptor expression. J Immunol 170: 503-507, 2003.

23. Pritts T, Hungness E, Wang Q, Robb B, Hershko D and Hasselgren PO: Mucosal and enterocyte IL-6 production during sepsis and endotoxemia-role of transcription factors and regulation by the stress response. Am J Surg 183: 372-383, 2002.

24. Liz J and Esteller M: IncRNAs and microRNAs with a role in cancer development. Biochim Biophys Acta 1859: 169-176, 2016

25. Varshney J and Subramanian S: MicroRNAs as potential target in human bone and soft tissue sarcoma therapeutics. Front Mol Biosci 2: 31, 2015.

26. Witwer KW, Sisk JM, Gama L and Clements JE: MicroRNA regulation of IFN-beta protein expression: Rapid and sensitive modulation of the innate immune response. J Immunol 184: 2369-2376, 2010.

27. Jones MR, Quinton LJ, Blahna MT, Neilson JR, Fu S, Ivanov AR, Wolf DA and Mizgerd JP: Zcchc11-dependent uridylation of microRNA directs cytokine expression. Nat Cell Biol 11: 1157-1163, 2009.

28. Rogler CE, Levoci L, Ader T, Massimi A, Tchaikovskaya T, Norel R and Rogler LE: MicroRNA-23b cluster microRNAs regulate transforming growth factor-beta/bone morphogenetic protein signaling and liver stem cell differentiation by targeting Smads. Hepatology 50: 575-584, 2009.

29. Luzi E, Marini F, Sala SC, Tognarini I, Galli G and Brandi ML: Osteogenic differentiation of human adipose tissue-derived stem cells is modulated by the miR-26a targeting of the SMAD1 transcription factor. J Bone Miner Res 23: 287-295, 2008.
30. Chen L, Zheng J, Zhang Y, Yang L, Wang J, Ni J, Cui D, Yu C and Cai Z: Tumor-specific expression of microRNA-26a suppresses human hepatocellular carcinoma growth via cyclin-dependent and -independent pathways. Mol Ther 19: 1521-1528, 2011.

31. Lu J, He ML, Wang L, Chen Y, Liu X, Dong Q, Chen YC, Peng Y, Yao KT, Kung HF and Li XP: MiR-26a inhibits cell growth and tumorigenesis of nasopharyngeal carcinoma through repression of EZH2. Cancer Res 71: 225-233, 2011.

32. Zhang B, Liu XX, He JR, Zhou CX, Guo M, He M, Li MF, Chen GQ and Zhao Q: Pathologically decreased miR-26a antagonizes apoptosis and facilitates carcinogenesis by targeting MTDH and EZH2 in breast cancer. Carcinogenesis 32: 2-9, 2011.

33. Kota J, Chivukula RR, O'Donnell KA, Wentzel EA, Montgomery CL, Hwang HW, Chang TC, Vivekanandan P, Torbenson M, Clark KR, et al: Therapeutic microRNA delivery suppresses tumorigenesis in a murine liver cancer model. Cell 137: 1005-1017, 2009.

34. Ciarapica R, Russo G, Verginelli F, Raimondi L, Donfrancesco A, Rota R and Giordano A: Deregulated expression of miR-26a and Ezh2 in rhabdomyosarcoma. Cell Cycle 8: 172-175, 2009.

35. Yang X, Liang L, Zhang XF, Jia HL, Qin Y, Zhu XC, Gao XM, Qiao P, Zheng Y, Sheng YY, et al: MicroRNA-26a suppresses tumor growth and metastasis of human hepatocellular carcinoma by targeting interleukin-6-Stat3 pathway. Hepatology 58: $158-170,2013$ 